\title{
Continuous modelling of the Bouregreg watershed (Morocco) using the HEC-HMS model
}

\author{
Oussama Laassilia ${ }^{1 *}$, Driss Ouazar $^{1}$, Ahmed Bouziane ${ }^{1}$, and Moulay Driss Hasnaoui ${ }^{2}$ \\ ${ }^{1}$ Hydraulique Systems Analysis Laboratory, Mohammadia School of Engineers, Mohammed V University in Rabat, Morocco. \\ ${ }^{2}$ Water Resources Division, Water Department, Ministry of Equipment, Transport, Logistics and Water, Rabat, Morocco.
}

\begin{abstract}
A deep understanding of the rainfall-runoff mechanism is essential to estimate the runoff generated in a given basin. In this regard, this paper aims to develop a continuous hydrological model of the Bouregreg watershed. The objective of this modelling is to evaluate the inflow to the Sidi Mohamed Ben Abdellah (SMBA) dam, located at the outlet of this basin. To this end, using the HEC-HMS model, the Soil Moisture Accounting (SMA) Loss Method was used to model infiltration losses. The SCS Unit hydrograph (SCS UH) and the Recession method were chosen as transform model and baseflow model, respectively. As a result, the comparison shows an acceptable agreement between observed and simulated flow in terms of streamflow distribution and peak values ( $\mathrm{NSE}=0.57, \mathrm{R}^{2}=0.58$ ). During validation, the model retained its ability to sufficiently reproduce the rainfall-runoff mechanism of the studied basin with a slight overestimation of peaks (NSE $=0.61, \mathrm{R}^{2}=0.60$ ). This study allows to assess and predict the inter-annual and intra-annual variation of the SMBA dam reservoir' inflows, and therefore to forecast the climate change impact on this basin.
\end{abstract}

\section{Introduction}

The Sidi Mohammed Ben Abdellah (SMBA) dam ensure, since 1974, the domestic and industrial water supply to the region of Rabat - Casablanca, and allow to protect the Bouregreg valley against floods. In addition, the SMBA dam is part of the hydraulic structures linked to the projected North-South water transfer project (NSWTP) in Morocco [1]. For that, developing a hydrological model of the SMBA dam basin is essential to assess the inter-annual and intra-annual variation of this reservoir's inflows. In addition, this model makes it possible to simulate the climate change impact on the SMBA's inflow and therefore evaluate the efficiency of the NSWTP. In this regard, few studies have analyzed the hydrologic behaviour of the Bouregreg basin [2-3]. However, those studies are either limited to one subbasin or a short period of simulation. Therefore, this paper aims to comprehensively calibrate and validate a hydrological model of the Bouregreg basin. The performance evaluation and sensitivity analysis are also undertaken.

Several hydrological models are designed for runoff estimation. The kind of modelling approach mainly depends on the aim of the study, data availability and ease of use [4]. HEC-HMS is a rainfall-runoff lumped model; it uses empirical methods to convert rainfall depth to runoff. The resulting hydrographs of HECHMS are usually used to study the flow forecasting, water availability, urban drainage, flood damage reduction and floodplain regulation [5]. Previous studies on HEC-HMS proved its ability to simulate and forecast streamflow based on different datasets and catchment types [6-8]. For that, the authors have selected HECHMS model to carry out this study.

\section{Materials and methods}

\subsection{Presentation of the Bouregreg basin}

The Bouregreg watershed covers an area of $9970 \mathrm{~km}^{2}$. It is bordered in the north by the Sebou basin and the Oum Rbia basin in the south. The SMBA dam is the outlet of the studied river basin (Figure 1). The hydrographic network is composed of three main rivers, namely the Bouregreg River $(130 \mathrm{~km})$, the Grou River $(270 \mathrm{~km})$, and the Mechra River $(95 \mathrm{~km})$. The climate is generally semi-arid with an average precipitation of 400 $\mathrm{mm} / \mathrm{yr}$, and the air average temperature varies between $10^{\circ} \mathrm{C}$ and $26^{\circ} \mathrm{C}$ [2]. The mean volume of the SMBA dam's inflows is about $530 \mathrm{Mm}^{3} /$ year (1975-2020) with a maximum of $2600 \mathrm{Mm}^{3}$ in 2010.

\subsection{Data used}

Basic information on topographic characteristics of the Bouregreg basin was extracted from a $30 \mathrm{~m}$ resolution Digital Elevation Model (DEM) of the study area, which is freely available online. The HECGeoHMS plugin was used to process the DEM data further [9].

\footnotetext{
* Corresponding author: oussama.laassilia90@gmail.com
} 


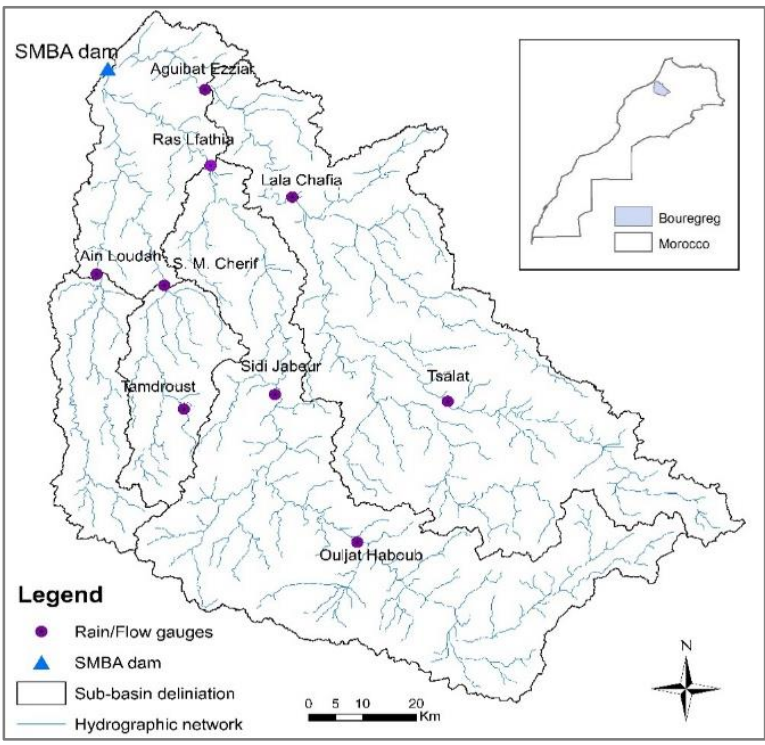

Fig. 1. Map of the Bouregreg Watershed.

Considering the spatial and temporal climate variability, rainfall, temperatures, and runoff data, at daily time step, were used (Table 1). These data were made available by the Water Research and Planning Direction. The incomplete data has been estimated using statistical regression with other gauges. Available data over the period 1975-1996 was used to calibrate the model, while the validation was carried out using the available data from 1997 to 2018.

Table 1. Hydroclimatic gauges used for Bouregreg basin modelling

\begin{tabular}{|c|c|c|c|}
\hline \multirow{2}{*}{ Rain gauges } & \multirow{Z}{Z}{$\begin{array}{c}\text { Z } \\
(\mathbf{m})\end{array}$} & \multicolumn{2}{|c|}{$\begin{array}{c}\text { Daily rainfall and runoff } \\
\text { availability }\end{array}$} \\
\cline { 3 - 4 } & & Start & End \\
\hline Aguibat Ezziar & 130 & $25 / 03 / 1977$ & $31 / 01 / 2018$ \\
\hline Ras Elfathia & 161 & $25 / 03 / 1977$ & $31 / 01 / 2018$ \\
\hline S. M. Cherif & 299 & $01 / 11 / 1972$ & $31 / 01 / 2018$ \\
\hline Lala Chafia & 227 & $01 / 09 / 1980$ & $31 / 01 / 2018$ \\
\hline Ain Loudah & 273 & $01 / 10 / 1972$ & $31 / 01 / 2018$ \\
\hline Tsalat & 692 & $01 / 03 / 1977$ & $31 / 01 / 2018$ \\
\hline Sidi Jabeur & 232 & $17 / 12 / 1971$ & $31 / 01 / 2018$ \\
\hline Ouljat Haboub & 552 & $01 / 11 / 1972$ & $31 / 01 / 2018$ \\
\hline Tamdroust & 312 & $01 / 09 / 1974$ & $31 / 01 / 2018$ \\
\hline
\end{tabular}

\subsection{Modelling formalisms}

The Bouregreg watershed is composed of four subbasins (Aguibat Ezziar, Ras Lfathia, S.M. Cherif and Ain Loudah) (Figure 1). Basin model in HEC-HMS is set-up using two hydrologic elements: sub-basin and junction. The sub-basin element handles the infiltration loss and rainfall-runoff transformation process. The junction element comprises the observed flow data to compare the simulated hydrographs with the observed one. In this study, we opted for semi-distributed modelling with a daily time step. The Soil Moisture Accounting (SMA) Loss Method was employed to model infiltration losses combined with canopy and surface methods. The SCS Unit hydrograph (SCS UH) and the Recession method were chosen as transform model and baseflow, respectively. The adopted methods have the advantage of the availability of data, stability, wide acceptability, limitations of other methods, and well-established researcher recommendations $[6,10]$.

\subsection{Initial values estimation}

Table 2 present the initial values for the SMA method. The initial soil content, the groundwater 1 initial content and the groundwater 2 initial content parameters were set to zero $\%$, assuming that the simulation starts after a prolonged dry period. The maximum infiltration rate was estimated as the upper limit of water entry from surface storage into the ground [11]. The values for maximum infiltration rate were obtained based on the soil analysis in the catchment and represent the saturated hydraulic conductivity [11]. Soil water storage value is similar to the porosity one [12]. The impervious area was defined as the surface which is directly connected to the streamflow as the urban zones or the water plans.

Table 2. Initial value estimation for the SMA model parameters

\begin{tabular}{|c|c|c|c|c|c|}
\hline \multirow[b]{2}{*}{ Methods } & \multirow[b]{2}{*}{ Parameters } & \multicolumn{4}{|c|}{ Initial values retained for each sub-basins } \\
\hline & & $\begin{array}{c}\text { Aguibat } \\
\text { Ezziar }\end{array}$ & $\begin{array}{c}\text { Ras } \\
\text { Lfathia }\end{array}$ & $\begin{array}{l}\text { S. M. } \\
\text { Cherif }\end{array}$ & $\begin{array}{c}\text { Ain } \\
\text { Loudah }\end{array}$ \\
\hline \multirow{2}{*}{$\begin{array}{c}\text { Simple } \\
\text { Canopy }\end{array}$} & Initial canopy storage (\%) & 0 & $\mathbf{0}$ & 0 & 0 \\
\hline & Maximum canopy storage (mm) & 1.65 & 1.42 & 1.38 & 1.27 \\
\hline \multirow{2}{*}{$\begin{array}{l}\text { Simple } \\
\text { Surface }\end{array}$} & Initial surface storage (\%) & 0 & 0 & 0 & 0 \\
\hline & Maximum surface storage $(\mathrm{mm})$ & 28.42 & 22.54 & 13.21 & 12.67 \\
\hline \multirow{14}{*}{ SMA } & Soil (\%) & $\mathbf{0}$ & $\mathbf{0}$ & $\mathbf{0}$ & 0 \\
\hline & Groundwater 1 (\%) & 0 & 0 & 0 & 0 \\
\hline & Groundwater 2 (\%) & $\mathbf{0}$ & $\mathbf{0}$ & 0 & 0 \\
\hline & Max infiltration rate $(\mathrm{mm} / \mathrm{h})$ & 4.21 & 5.36 & 2.16 & 2.05 \\
\hline & Impervious (\%) & 0.46 & 0.64 & 0.11 & 0.26 \\
\hline & Soil storage (mm) & 423.26 & 406.87 & 385.45 & 366.14 \\
\hline & Tension storage (mm) & 316.33 & 344.26 & 284.36 & 275.33 \\
\hline & Soil percolation $(\mathrm{mm} / \mathrm{h})$ & 4.21 & 5.36 & 2.16 & 2.05 \\
\hline & GW 1 percolation $(\mathrm{mm} / \mathrm{h})$ & 4.21 & 5.36 & 2.16 & 2.05 \\
\hline & GW 2 percolation $(\mathrm{mm} / \mathrm{h})$ & - & - & - & - \\
\hline & GW 1 storage (mm) & 2.06 & 1.89 & 0.68 & 0.54 \\
\hline & GW 1 coefficient (h) & 21.42 & 36.84 & 12.33 & 10.97 \\
\hline & GW 2 storage $(\mathrm{mm})$ & 8.65 & 8.32 & 4.65 & 4.21 \\
\hline & GW 2 coefficient (h) & 87.65 & 75.04 & 42.16 & 40.65 \\
\hline
\end{tabular}

Tension storage was determined based on the tables correlating soil texture class to porosity and field capacity [12]. The soil percolation rate and the groundwater layers (GW1 \& GW2) percolation rate were chosen as the average hydraulic conductivity [12]. Storage coefficients and depths of GW1 and GW2 were determined based on a streamflow recession analysis of historical flow data [11].

The lag time $\left(\mathrm{T}_{\mathrm{lag}}\right)$, defined as the time from the centroid of rainfall excess to the centroid of direct runoff, is calculated for each sub-basin based on the time of concentration $\mathrm{T}_{\mathrm{c}}$, as:

$$
\mathrm{T}_{\text {lag }}(\min )=0.6 \mathrm{~T}_{\mathrm{c}}(\mathrm{min})
$$

The $T_{c}$ was calculated using the various methods existing in the literature [13]. Thus, the retained value of the $T_{c}$ corresponds to the average of the convergent values (Table 3 ). 
Table 3. Representative $\mathrm{Tc}$ and $\mathrm{T}_{\mathrm{lag}}$ for different sub-basin of the Bouregreg watershed

\begin{tabular}{|c|c|c|}
\hline Sub-basin & $\mathrm{T}_{\mathrm{c}}(\mathrm{min})$ & $\mathrm{T}_{\text {lag }}(\min )$ \\
\hline Aguibat Ezziar & 515 & 309 \\
\hline Ras Lfathia & 506 & 304 \\
\hline S.M. Cherif & 151 & 91 \\
\hline Ain Loudah & 166 & 100 \\
\hline
\end{tabular}

The Recession method uses an exponentially declining baseflow developed from standard baseflow separation techniques. However, given the unavailability of information to assign an initial value for the Recession constant $\left(R_{c}\right)$ and the Threshold $\left(T_{d}\right)$, a value from literature has been used for the calibration of these parameters [14]. The recession constant $R_{c}$ is set at 0.5 and the threshold $\mathrm{Td}$ at 0.3 . Only the initial baseflow at the beginning of the episode is necessary.

\subsection{Model Calibration and Validation}

The auto-calibration, through optimization trials, was used to optimize the estimates of the model parameters. We choose the Weighted Root Mean Square Error as the objective function in the calibration process, which has the advantage of considering both the magnitude and temporal synchronization of the flood. The validation process aims to expose a calibrated model to other events different from that used for calibration. The objective is to assess the model capability to reproduce the hydrograph shape accurately, especially the peak flow.

\subsection{Performance evaluation criteria}

HEC-HMS model performance evaluation involves assessing the goodness of fit in the observed and simulated streamflow using Statistical techniques as shown in table 4.

Table 4. Performance evaluation criteria [11]

\begin{tabular}{|c|c|}
\hline Evaluation criterion & Formula \\
\hline $\begin{array}{l}\text { The Percentage Error in Volume } \\
\text { (PEV) }\end{array}$ & $\mathrm{PEV}=\left|\frac{\mathrm{Vol}_{\mathrm{o}}-\mathrm{Vol}_{\mathrm{os}}}{\mathrm{Vol}_{\mathrm{o}}}\right|$ \\
\hline $\begin{array}{l}\text { The percentage Error in Peak Flow } \\
\text { (PEPF) }\end{array}$ & PEPF $=\left|\frac{Q_{0}(\text { peak })}{-Q_{s}(\text { peak })}\right|$ \\
\hline The Coefficient of correlation $\left(R^{2}\right)$ & $R^{2}=\left[\frac{\sum_{i=1}^{n}\left(O_{i}-\bar{O}\right) *\left(S_{i}-\bar{S}\right)}{\sum_{i=1}^{n}\left(O_{i}-\bar{O}\right)^{2} *\left(\left(S_{i}-\bar{S}\right)\right)^{2}}\right]^{2}$ \\
\hline The index of agreement (d) & $\mathbf{d}=\mathbf{1}-\frac{\sum_{\mathrm{i}=1}^{\mathrm{n}}\left(\mathbf{0}_{\mathrm{i}}-\mathbf{S}_{\mathrm{i}}\right)^{2}}{\sum_{\mathrm{i}=1}^{\mathrm{n}}\left(\left|\mathbf{S}_{\mathrm{i}}-\overline{\mathbf{S}}\right|+\left|\mathbf{0}_{\mathrm{i}}-\overline{\mathbf{0}}\right|\right)^{2}}$ \\
\hline $\begin{array}{l}\text { The Nash-Sutcliffe model Efficiency } \\
\text { (NSE) }\end{array}$ & $\mathrm{NSE}=\frac{\sum_{\mathrm{i}=1}^{\mathrm{n}}\left(\mathbf{0}_{\mathrm{i}}-\mathrm{S}_{\mathrm{i}}\right)^{2}}{\sum_{\mathrm{i}=1}^{\mathrm{n}}\left(\mathbf{0}_{\mathrm{i}}-\overline{\mathbf{0}}\right)^{2}}$ \\
\hline The absolute error index (RSR) & $\mathrm{RSR}=\frac{\sqrt{\sum_{i=1}^{n}\left(\boldsymbol{o}_{i}-S_{i}\right)^{2}}}{\sqrt{\sum_{i=1}^{n}\left(\boldsymbol{o}_{i}-\overline{\boldsymbol{O}}\right)^{2}}}$ \\
\hline
\end{tabular}

Where: $\mathrm{Vol}_{\mathrm{o}}$ and $\mathrm{Vol}_{\mathrm{s}}$ are the observed and simulated volumes, respectively. $\mathrm{Q}_{\mathrm{o}(\text { peak) }}$ and $\mathrm{Q}_{\mathrm{s}(\text { peak) }}$ are the observed and simulated flows, respectively. $\boldsymbol{O}_{i}$ and $S_{i}$ are the observed and simulated flows at the time i, respectively, and $\overline{\mathbf{0}}, \overline{\mathbf{S}}$ are the average observed and simulated flows during the calibration period, respectively. To interpret the results, general performance ratings for recommended statistics, according to [11-12], are used.

\subsection{Sensitivity Analysis}

Sensitivity analysis is an essential operation in the hydrologic modeling process because it allows identifying the most influential parameters on the model outputs. In other words, a slight change in the value of those parameters can lead to a significant variation in the simulated flow. Therefore, the most sensitive parameters of the model need to be precisely estimated. In this study, the values of five parameters were varied from $-30 \%$ to $+30 \%$ in increments of $10 \%$, keeping all other parameters constant. Then, the output values (simulated volume, peaks, and NSE) were analyzed to determine variation with respect to the initial estimates of the parameters.

The elasticity ratio $(\boldsymbol{e})$ was used to identify the most sensitive parameter. Also called the relative sensitivity, $\boldsymbol{e}$ expresses the relative change in the dependent variable with respect to the independent variable [11].

$$
e=\frac{\Delta O / O}{\Delta I / I}=\frac{\% \text { change }_{\text {output }}}{\% \text { change }_{\text {input }}}
$$

Where $O$ and $I$ are the output and the input variables, respectively. More excellent elasticity ratio indicates a more highly sensitive variable.

\section{Results and discussion}

At first glance, the recorded flows series show that the four sub-basins have practically the same hydrological regime. However, the runoff generated differs from one sub-basin to another according to the surface area of each one. As for the simulation results, the comparison shows an acceptable agreement between simulated and observed streamflow in terms of peak values and streamflow distribution. The parameters were optimized to obtain a closer agreement between the simulated and observed flow.

Regarding the optimization results, the maximum canopy storage and maximum surface storage values have been slightly raised, while impervious, soil percolation, GW1 and GW2 storage have been reduced. We mention that the optimized value of tension storage parameter has been significantly increased compared to the estimated value. We also note that some parameter values have not been changed after the optimization namely, GW1 coefficient and maximum infiltration rate for Ras Lfathia and Ain Loudah sub-basins. As a result, the model quality was much improved after the optimization of the initial parameters. 

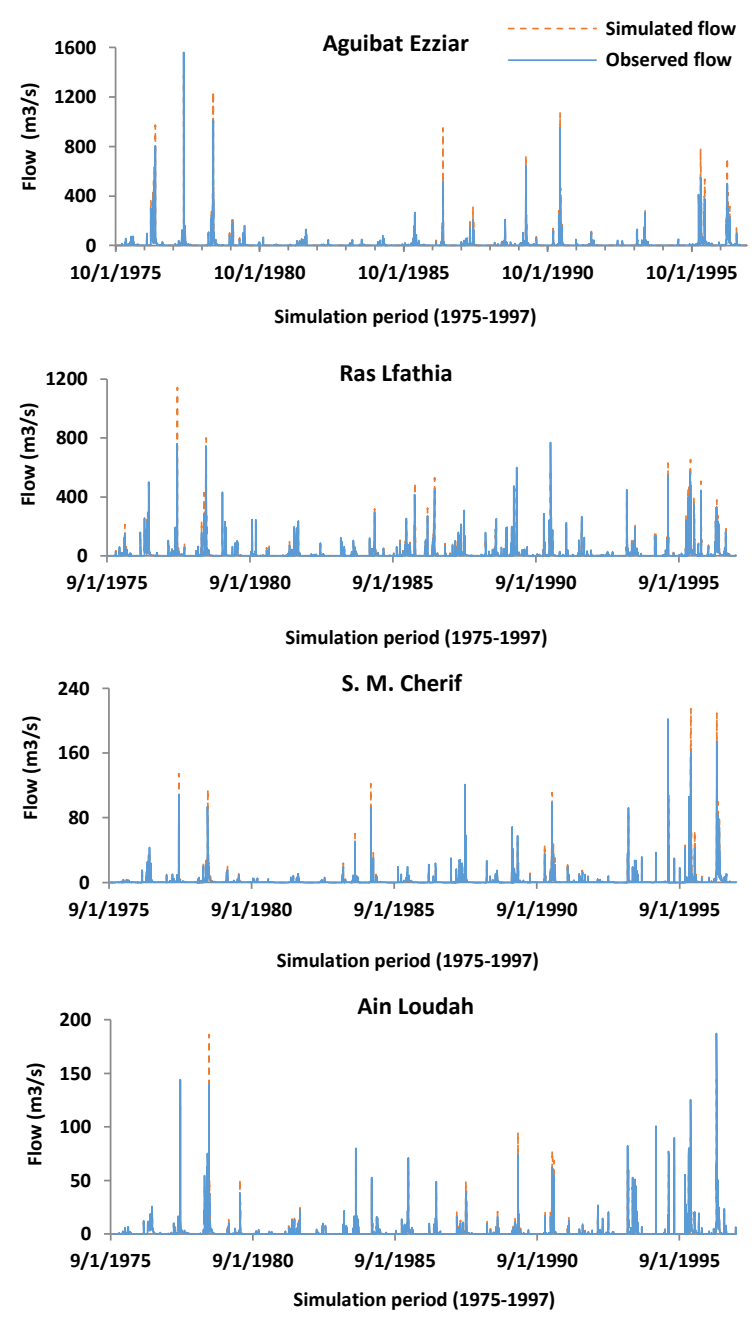

Fig. 2. Observed and simulated hydrographs for the various Bouregreg sub-basins during calibration.

During validation, the model thus calibrated retained its ability well to reproduce the rainfall-runoff mechanism of the studied basin. Therefore, the simulation made over a long period of more than 20 years, including several successions of rainy and dry periods, was well simulated with a slight overestimation of peaks for all the basins. However, the simulated and observed streamflow comparison graphs show an acceptable agreement regarding the streamflow.

As for the model performance evaluation, table 5 shows a low percentage error in volume for all subbasins; the PEV evaluation, during calibration, is good to very good. Similarly, the peak flow has been well reproduced, although the model tends to overestimates the peak for some events. Then, the PEPF range from $10.65 \%$ for Ain Loudah sub-basin to $26.25 \%$ for Ras Lfathia sub-basin. During validation, the model performance evaluation has been slightly degraded, especially for Ras Lfathia sub-basin. Nevertheless, the evaluation results are globally satisfactory. The Coefficient of correlation $\left(\mathrm{R}^{2}\right)$ and the NSE criteria show good results during calibration and satisfactory results during validation.
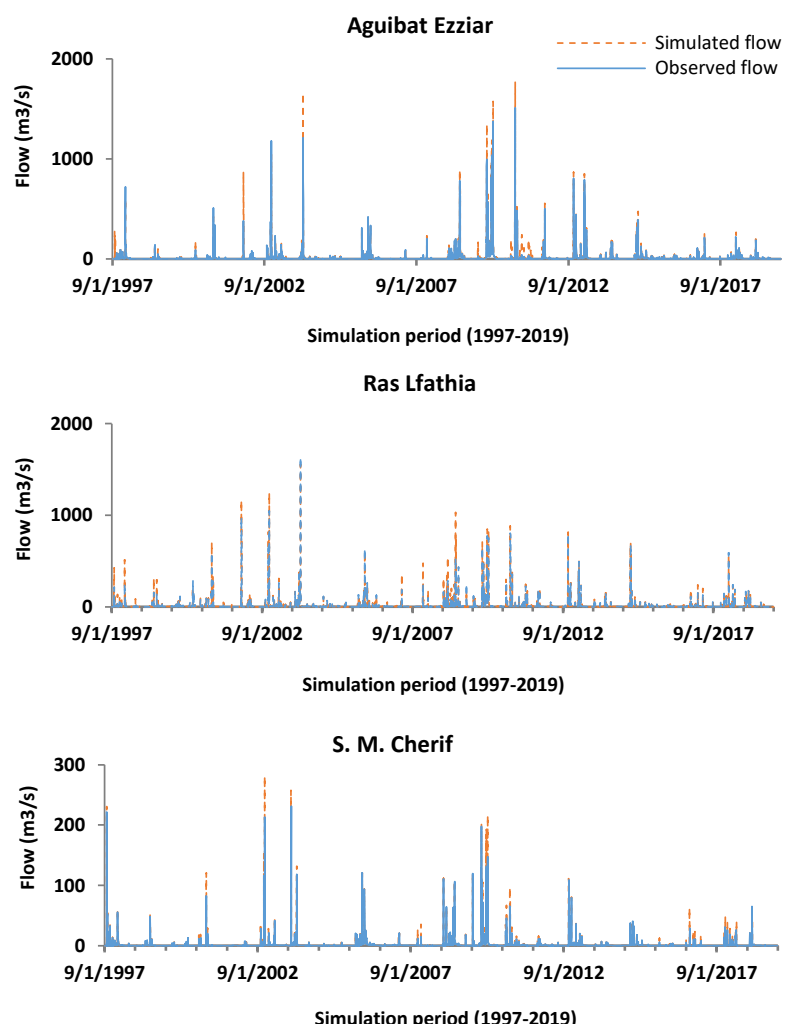

Ain Loudah

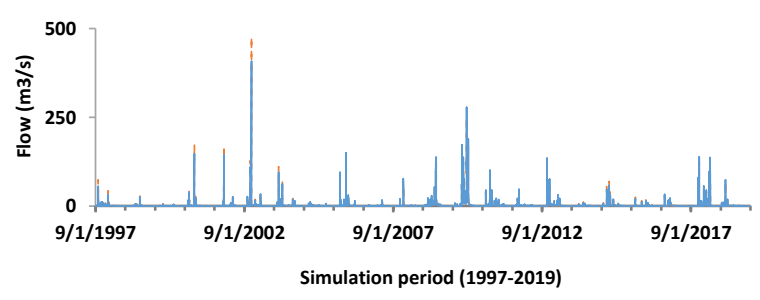

Fig. 3. Observed and simulated hydrographs for the various sub-basins of Bouregreg during validation

The NSE for S.M. Cherif and Ain Loudah sub-basins is about 0.7 and is about 0.63 for Aguibat Ezziar and Ras Lfathia sub-basins. During validation, the NSE criterion was also degraded but still satisfactory, except Ras Lfathia sub-basin (NSE=0.48). The index of agreement (d) is evaluated as good to very good for all the subbasins, both during calibration and validation. The Root Mean Squared Error (RMSE), which indicates the appropriateness of the model simulation, also show satisfactory to good results, except Ras Lfathia and S.M. Cherif sub-basins during validation.

Table 5. Performance evaluation of the developed continuous model during calibration and validation

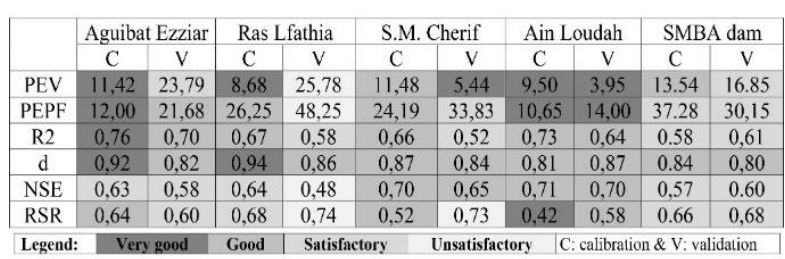

After calibrating and validating the hydrological model for each sub-basin, it becomes possible to test a model at the scale of the entire Bouregreg basin to model 
the inflows to the SMBA dam. An intermediate subbasin was added to the already developed models, in which the initial parameters have been estimated based on the same methods used previously. The parameters obtained previously by calibration for the different subbasins were kept. As a result, the simulated and observed flows at the Bouregreg outlet are roughly comparable. The tested performance criteria show satisfactory to good results during calibration, with a slight decrease in PEV and PEPF, and a minor improvement for the NSE and $\mathrm{R}^{2}$ criteria during validation. Therefore, the developed hydrologic model makes it possible to simulate the inflows to the SMBA dam reservoir successfully.
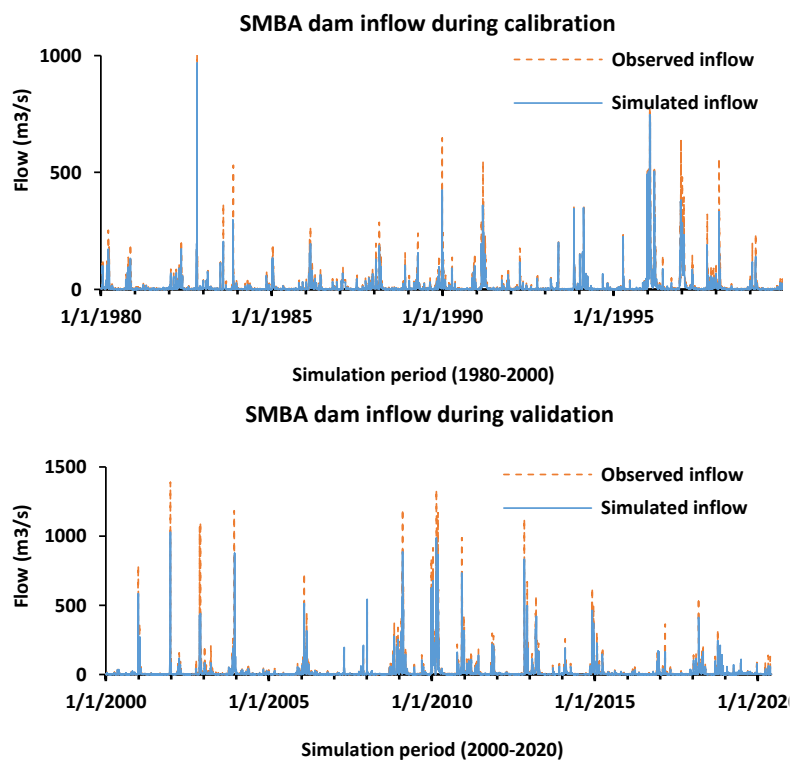

Fig. 4. Observed and simulated inflow to the SMBA dam during calibration and validation

Sensitivity analysis was done to determine the sensitivity of the calculated volume, the simulated peak, and the NSE value to some of the SMA model parameters, namely the maximum canopy storage, the maximum surface storage, the maximum infiltration rate, the impervious, the soil storage, and the soil percolation (Figure 5).

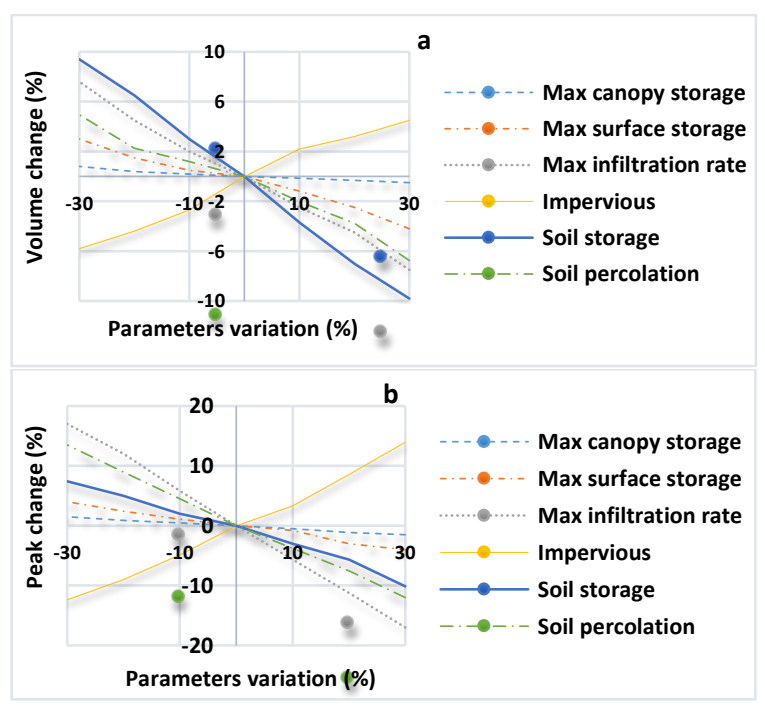

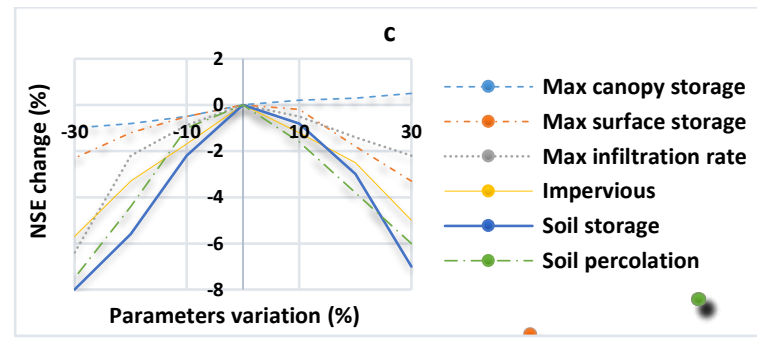

Fig. 5. Percentage changes in simulated volume (a), peak (b), and NSE (c) plotted against the percentage variation of each parameter.

As a result, the runoff volume is more sensitive to soil storage, max infiltration rate, and impervious. In contrast, the peak flow was found to be more sensitive to max infiltration rate, impervious and Soil percolation. Concerning the NSE criterium, it is more sensitive to soil storage, Soil percolation, and impervious, respectively (Table 6). However, max canopy storage is the least sensitive parameter.

Table 6. SMA parameters sensitivity ranking for volume, peak and NSE

\begin{tabular}{|c|c|c|c|}
\hline Parameters & Volume & Peak & NSE \\
\hline Max canopy storage & 0.02 & 0.08 & 0.03 \\
\hline Max surface storage & 0.10 & 0.17 & 0.05 \\
\hline Max infiltration rate & 0.23 & $\underline{\mathbf{0 . 6 2}}$ & 0.06 \\
\hline Impervious & 0.20 & 0.54 & 0.08 \\
\hline Soil storage & $\underline{\mathbf{0 . 3 3}}$ & 0.35 & $\underline{\mathbf{0 . 1 1}}$ \\
\hline Soil percolation & 0.17 & 0.51 & 0.10 \\
\hline
\end{tabular}

\section{Conclusion}

In conclusion, the HEC-HMS model was successfully calibrated and validated in the Bouregreg watershed, which confirms the applicability of this model in the semi-arid climate context. The model performance evaluation was carried out successfully with the frequent used statistical evaluation criteria. In this context, the percentage errors in volume (PEV) was about $13 \%$ for the calibration and $17 \%$ for the validation process reflecting a good model fit. In contrast, the percentage errors in peak (PEPF) was $37 \%$ and $30 \%$ for the calibration and validation periods, respectively, which still remains a satisfactory result. The global NSE criterion was 0.57 for the calibration and 0.60 for the validation which is generally a satisfactory result. Similarly, the coefficients of determination $\left(\mathrm{R}^{2}\right)$ for the calibration and validation periods were 0.58 and 0.61 , respectively. the indices of agreement (d) were 0.84 and 0.80 during the calibration and validation periods, respectively, indicating a good model fit. The RSR, which assesses the appropriateness of the model, ranged from 0.66 to 0.68 for the calibration and validation period, indicating acceptable performance. Regarding these results, the SMA model in the HEC-HMS model can be used to predict continuous daily streamflow in the Bouregreg catchment. Sensitivity analysis of the 
continuous model was performed and showed that the runoff volume was more sensitive to soil storage, max infiltration rate, and impervious, while the peak volume was more sensitive to max infiltration rate, impervious and Soil percolation. At the same time, the NSE was found to be more sensitive to soil storage, Soil percolation, and impervious, respectively. Max canopy storage was found to be the least sensitive parameter.

The elaborated model could be very useful to predict the SMBA dam's inflows both in present and future. In addition, simulation of the future runoff allows to forecast the climate change impact on the NSWTP efficiency.

\section{References}

1. O. Laassilia, D. Ouazar, A. Bouziane, M.D. Hasnaoui, ICOA $5^{\text {th }}$, Kenitra, Morocco (2019)

2. A. Fadil, H. Rhinane, A. Kharchaf, O. A. Bachir, J. of Geo. Inf. Sys. 3, 4(2011)

3. M. Khattati, M. Serroukh, I. Rafik, H. Mesmoudi, B. Hassane, Y. Bouslihim, J. of Geos. and Env. Pro. 4, 77(2016)

4. K.T. Chang, A. Talei, S. Alaghmand, O.M. PoLeen, J. of Hydr. 545, 108(2016)

5. US Army Corps of Engineers, Quick Start Guide, Institute for Wat. Res. Hyd. Eng. Center, USA (2015)

6. A. Ahbari, L. Stour, A. Agoumi, N. Serhir, Arab. J. of Geos. 11, 18(2018)

7. T.C. De Moraes, V.J. Calijuri, F.T.P. Torres, Env. Ear. Sci. 77, 6(2018)

8. T. Nharo, H. Makurira, W. Gumindoga, Phy. and Chem. of the Ear. Parts A/B/C (2019)

9. O. Laassilia, D. Ouazar, A. Bouziane, M.D. Hasnaoui, J. of App. Wat. Eng. and Res. 9:1, 69-87, (2021)

10. B.G. Tassew, M.A. Belete, K. Miegel, J. of Hydr. 6, 21(2019)

11. W. Ouédraogo, J. Raude, J. Gathenya, Hydrology. 5, 3(2018)

12. M. Fleming, Master's Thesis, Tennessee Technological University, USA (2002)

13. A. Azizian, A. J. of Eng. App. Sci. 11, 1 (2018)

14. Y. Tramblay, IRDH, France (2012) 